Polymer Journal, Vol. 38, No. 9, pp. 956-960 (2006)

(C) 2006 The Society of Polymer Science, Japan

\title{
Synthesis of Poly(naphthylene ether) Containing Tetraphenylmethane Group with a Low Dielectric Constant
}

\author{
Kousuke TSUCHIYA and Mitsuru UEDA ${ }^{\dagger}$ \\ Department of Organic and Polymeric Materials, Graduate School of Science and Engineering, \\ Tokyo Institute of Technology, 2-11-1 Ookayama, Meguro-ku, Tokyo 152-8552, Japan
}

(Received March 6, 2006; Accepted June 14, 2006; Published August 11, 2006)

\begin{abstract}
A novel thermally stable and low dielectric poly[4,4'-bis(1-naphthyloxy)tetraphenylmethane] (2) has been successfully prepared. 4,4'-Bis(1-naphthyloxy)tetraphenylmethane (1) as a monomer was synthesized by the Ullmann reaction from 4,4'-dihydroxytetraphenylmethane and 1-bromonaphthalene. The oxidative coupling polymerization of 1 was conducted in 1,1,2,2-tetrachloroethane with iron (III) chloride as an oxidant to afford polymer 2 with number-average molecular weights up to 19,000 . The 5\% weight loss and glass transition temperatures of 2 were $534^{\circ} \mathrm{C}$ and $258^{\circ} \mathrm{C}$, respectively. The dielectric constants $(\varepsilon)$ of polymer 2 estimated from the refractive index and the capacitance were 2.69 and 2.75, respectively. [doi:10.1295/polymj.PJ2005246]

KEY WORDS Low- $\kappa$ Material / Poly(naphthylene ether) / Thermal Stability / Oxidative Coupling Polymerization / Insulation Materials /
\end{abstract}

Scaling down of integrated circuit (IC) feature sizes has brought tremendous performance improvement and miniaturization in the past few decades, and the distance of the electrically conducting interconnect lines has extremely decreased. ${ }^{1}$ This trend induces resistance-capacitance time delay, crosstalk noise, and power dissipation, which can be improved by the use of either the more conductive metals or low dielectric constant $(\varepsilon)$ insulators. Many low dielectric constant insulating materials including inorganic, inorganic/ organic hybrids, and organic polymers such as poly(imide)s, poly(aryl ether)s, poly(ether ketone)s, heteroaromatic polymers, and fluoropolymers ${ }^{2}$ have been proposed. However, these organic polymers basically comprise high polar aromatic backbone, which results in higher $\varepsilon$ values except costly perfluoropolymers. ${ }^{3}$

Recently porous materials have been attracted much attention for low- $\kappa$ insulators since pores make the density of materials significantly low. ${ }^{4}$ Lower $\varepsilon$ value can be achieved with pores included inside materials; in the meantime these materials hardly maintain mechanical properties to meet with industrial requirements. Furthermore the high $\varepsilon$ materials such as an silicon oxide ( $\varepsilon \sim 3.9$ to 4.5$)$ needs at most 70 percents of pores introduction to reach $\varepsilon<2.0$, which may cause short circuit or metal diffusion through the unisolated pores.

Organic low- $\kappa$ polymers with much free volume in themselves have also been prepared, mechanical properties of which surpass that of porous materials. Swager et al. demonstrated that polymers incorporating the triptycene moiety have pores with a diameter of less than $45 \AA$ by BET gas absorption, which result- ed in low dielectric constants. ${ }^{5}$ Another example of bulky low- $\kappa$ polymer is SiLK manufactured by Dow Chemical with high thermal and mechanical properties, but cross-linked system by high thermal treatment is not suitable for industrial process. ${ }^{6}$

On the other hand, we developed a series of poly(naphthylene ether)s 3 and 4 by oxidative coupling polymerization that can produce linear polymers in convenient process, ${ }^{7,8}$ and showed that these polymers have the low dielectric constants of 2.5-2.8, which is maybe explained by molecular size free volume created by their kinked structures due to the orthogonal bonding of naphthalene rings side by side. (Scheme 1) Poly(naphthylene ether)s 3 and 4, however, gave brittle films due to their rigid structure. It is important to prepare polymers giving flexible films as well as decreasing the molecular polarization and molecular density of polymers for the design of low- $\kappa$ polymers. Introducing a tetraphenylmethane group into polymers will be an effective method to decrease molecular density of polymers because of its bulky tetrahedral structure, which is similar to a 9,9-diphenylfluorene group known as a cardo structure. In addition, incorporation of tetraphenylmethane groups in the main

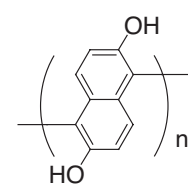

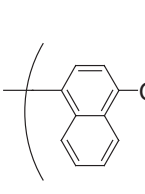

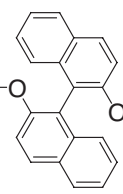

4

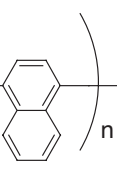

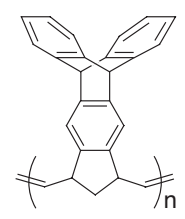

5
Scheme 1. 
chains will provide good film properties compared to that of binaphthyl groups that are too rigid to make a film flexible.

This paper describes the successful synthesis of poly[4,4'-bis(1-naphthyloxy)tetraphenylmethane] (2) by oxidative coupling polymerization of a novel naphthyloxy monomer, 4,4'-bis(1-naphthyloxy)tetraphenylmethane (1). The thermal stability and $\varepsilon$ value of 2 are also reported.

\section{EXPERIMENTAL}

\section{Materials}

Nitrobenzene was purified by vacuum distillation from calcium hydride. 4,4'-Dihydroxytetraphenylmethane was prepared from dichlorodiphenylmethane and phenol. ${ }^{9}$ Other chemicals were used as received.

\section{Synthesis of 4,4'-Bis(1-naphthyloxy)tetraphenylmeth- ane (1)}

To a two-necked flask equipped with a dean-stark apparatus were added 4,4'-dihydroxytetraphenylethane $(1.4 \mathrm{~g}, 4.0 \mathrm{mmol})$, sodium bicarbonate $(1.1 \mathrm{~g}, 8.0$ $\mathrm{mmol})$, quinoline $(4 \mathrm{~mL})$, and toluene $(10 \mathrm{~mL})$, then heated at $150^{\circ} \mathrm{C}$ for $2 \mathrm{~h}$ to remove water by azeotropy. After the formation of sodium salt, toluene was removed at $150^{\circ} \mathrm{C}$, then the solution was cooled down to room temperature. Cupper powder $(0.013 \mathrm{~g}$, $5 \mathrm{~mol} \%)$ and 1-bromonaphthalene $(1.2 \mathrm{~mL}, 8.0 \mathrm{mmol})$ were added to the solution, followed by heating the mixture at $200^{\circ} \mathrm{C}$ for $48 \mathrm{~h}$ under nitrogen atmosphere. After the reaction, the mixture was precipitated into the large amount of methanol, and the precipitate was filtrated and washed by methanol. The filtrate was extracted with methylene chloride and $1 \mathrm{~N} \mathrm{HCl}$ aq. and the organic portion was collected and evaporated. The crude product was purified by silica gel column chromatography eluted with hexane/toluene $(1 / 1)$ and recrystallized from 1,2-dichloroethane to yield $1.3 \mathrm{~g}$ of $1(54 \%) .{ }^{1} \mathrm{H}$ NMR $\left(\mathrm{CDCl}_{3}, 25^{\circ} \mathrm{C}\right.$, ppm): $\delta=6.92(\mathrm{~m}, 4 \mathrm{H}), 6.99(\mathrm{~d}, 2 \mathrm{H}), 7.17(\mathrm{~m}, 6 \mathrm{H}), 7.24(\mathrm{~m}$, $8 \mathrm{H}), 7.37(\mathrm{t}, 2 \mathrm{H}), 7.49(\mathrm{~m}, 4 \mathrm{H}), 7.60(\mathrm{~d}, 2 \mathrm{H}), 7.85(\mathrm{~m}$, 2H), $8.20(\mathrm{~m}, 2 \mathrm{H}) .{ }^{13} \mathrm{C} \mathrm{NMR}\left(\mathrm{CDCl}_{3}, 25^{\circ} \mathrm{C}, \mathrm{ppm}\right)$ : $\delta=63.97,113.60,117.29,122.11,123.40,125.77$, $125.89,125.94,126.03,126.59,126.91,127.53$, $127.78,131.08,132.49,141.57,146.86,152.89$, 155.87. IR (KBr, cm $\left.{ }^{-1}\right): 1234(\mathrm{C}-\mathrm{O}), 1577$ and 1596 $\left(\mathrm{C}=\mathrm{C}\right.$, aromatic). Anal. Calcd. for $\mathrm{C}_{45} \mathrm{H}_{32} \mathrm{O}_{2}: \mathrm{C}$, $89.38 \%, \mathrm{H}, 5.33 \%$. Found: C, $89.49 \%$, H, 5.65\%.

\section{Polymerization of 4,4'-(1-Naphthyloxy)tetraphenyl- methane}

A mixture of $1(0.10 \mathrm{~g}, 0.17 \mathrm{mmol})$ in 1,1,2,2-tetrachloroethane $(0.6 \mathrm{~mL}, 15 \mathrm{wt} \%)$ was heated until the solution turned completely clear. After cooling down to room temperature, iron (III) chloride $(0.067 \mathrm{~g}$, $0.42 \mathrm{mmol}$ ) was added to the solution under nitrogen atmosphere, and then stirred at room temperature for $48 \mathrm{~h}$. The reaction mixture was poured into methanol, and acidified with a small amount of hydrochloric acid. The polymer was filtrated and dissolved in chloroform, and the solution was precipitated into acetone. White polymer 2 was obtained after filtration. The yield was $0.092 \mathrm{~g}(92 \%) .{ }^{1} \mathrm{H}$ NMR $\left(\mathrm{CDCl}_{3}\right.$, $\left.25^{\circ} \mathrm{C}, \mathrm{ppm}\right): \delta=7.07(\mathrm{~m}, 6 \mathrm{H}), 7.29-7.43(\mathrm{~m}, 22 \mathrm{H})$, $8.35(\mathrm{~m}, 2 \mathrm{H}) \cdot{ }^{13} \mathrm{C} \mathrm{NMR}\left(\mathrm{CDCl}_{3}, 25^{\circ} \mathrm{C}, \mathrm{ppm}\right): \delta=$ $64.00,112.80,117.55, \quad 122.21, \quad 125.83,126.04$, $126.05,126.64,126.73,127.54,127.89,131.06$, $132.55,133.49,134.27,141.75,146.81,152.72$, 155.70. IR ( $\left.\mathrm{KBr}, \mathrm{cm}^{-1}\right): 1234(\mathrm{C}-\mathrm{O}), 1589(\mathrm{C}=\mathrm{C}$, aromatic). Anal. Calcd. for $\mathrm{C}_{45} \mathrm{H}_{30} \mathrm{O}_{2}: \mathrm{C}, 89.67 \%$, H, 5.02\%. Found: C, $89.13 \%, \mathrm{H}, 5.21 \%$.

\section{Measurement}

Infrared (IR) spectra were recorded on a Horiba FT-720 spectrophotometer. ${ }^{1} \mathrm{H}$ and ${ }^{13} \mathrm{C}$ NMR spectra were obtained on a JEOL JNM-AL400 spectrometer at 400 and $100 \mathrm{MHz}$, respectively. Deuterated chloroform was used as a solvent with tetramethylsilane as an internal standard. Number- and weight-average molecular weights $\left(M_{\mathrm{n}}\right.$ and $\left.M_{\mathrm{w}}\right)$ were determined by a gel permeation chromatograph (GPC) on a Jasco GULLIVER 1500 system equipped with a polystyrene gel column (Plgel $5 \mu \mathrm{m}$ MIXED-C) eluted with chloroform at a flow rate of $1.0 \mathrm{~mL} \mathrm{~min}^{-1}$ calibrated by standard polystyrene samples. Thermal analysis was performed on a Seiko EXSTAR 6000 TG/DTA 6300 thermal analyzer at a heating rate of $10^{\circ} \mathrm{C} /$ min for thermogravimetry (TG) and a Seiko EXSTAR 6000 DSC 6200 at a heating rate of $10^{\circ} \mathrm{C} / \mathrm{min}$ for differential scanning calorimetry (DSC) under nitrogen. The film was spin-coated on a silicone wafer from the polymer solution in toluene. The electrical properties were determined after vapor deposition of chromium with $6 \times 10^{-2} \mathrm{~cm}^{2}$ square on the surface of the film by using a precision LCR meter (Agilent $4284 \mathrm{~A} 1 \mathrm{MHz}$ ). This allowed measuring the capacitance and the breakdown voltage of the films. The dielectric constant $\varepsilon$ can be calculated from the capacitance using the formula $\varepsilon=c \mathrm{~d} / \mathrm{S} \varepsilon_{0}$, where $c$ is the observed capacity, $d$ the film thickness, $S$ the chromium area, and $\varepsilon_{0}$ the free permittivity. Refractive indices $(n)$ of polymer films formed on quartz substrates were measured at a wavelength of $1320 \mathrm{~nm}$ at room temperature with a Metricon model PC-2000 prism coupler. Using linearly-polarized laser light with parallel (TE: transverse electric) and perpendicular (TM: transverse magnetic) polarization to the film plane, the in-plane $\left(n_{\mathrm{TE}}\right)$ and out-of-plane $\left(n_{\mathrm{TM}}\right)$ refractive indices and the film thickness of the samples were deter- 


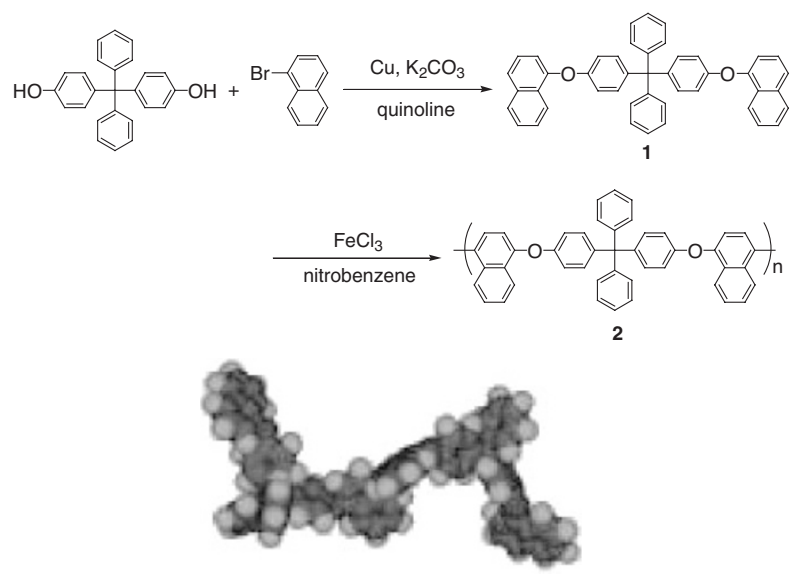

Scheme 2.

mined. The cyclic voltammogram was measured at room temperature in a typical three electrode with a working (Pt wire), a reference $(\mathrm{Ag} / \mathrm{AgCl})$, and a counter electrode (Pt spiral) under a nitrogen atmosphere at a sweeping rate of $10 \mathrm{mV} / \mathrm{s}$ (Hokuto Denko HSV-100). A $0.1 \mathrm{M}$ solution of tetrabutylammonium perchlorate (TBAP) in anhydrous acetonitrile was used as an electrolyte.

\section{RESULTS AND DISCUSSION}

\section{Synthesis of Monomer 1}

Decreasing the molecular density is an effective strategy for reduction of dielectric constant. Thus novel monomer 1 possessing a bulky backbone was designed and synthesized by the Ullmann reaction from 4,4'-dihydroxytetraphenylmethane and 1-bromonaphthalene using cupper catalyst shown in Scheme 2. The structure was confirmed by IR, ${ }^{1} \mathrm{H}$ NMR, and ${ }^{13} \mathrm{C}$ NMR. The IR spectrum of 1 clearly shows a characteristic absorption at $1234 \mathrm{~cm}^{-1}$ due to ether bond $(\mathrm{C}-\mathrm{O}-\mathrm{C})$ with disappearance of the absorption band due to $\mathrm{OH}$ groups. In the ${ }^{1} \mathrm{H}$ NMR spectrum of 1 (Figure 1a), the signals derived from 1-oxynaphthylene unit appear at $7.37(b), 7.85(d), 7.49(e, f)$ and $8.20(\mathrm{~g}) \mathrm{ppm}$, especially ortho- $(a)$ and para-positioned $(c)$ protons appear at 7.60 and $6.99 \mathrm{ppm}$ respectively. Figure $1 \mathrm{~b}$ shows the ${ }^{13} \mathrm{C}$ NMR spectrum of 1 , in which the signals assignable to carbons next to oxygen appear in downfield at $152.89 \mathrm{ppm}$ for $j$-position and $155.87 \mathrm{ppm}$ for $k$-position. In the meantime ortho-(a) and para-positioned (c) carbons of a 1-oxynaphthylene unit are assigned to 123.40 and 112.80 ppm respectively.

\section{Cyclic Voltammogram}

To determine a redox potential of monomer 1, it was measured in a $10 \mu \mathrm{M}$ acetonitrile solution containing 0.1 M TBAP in the cell equipped with a refer-
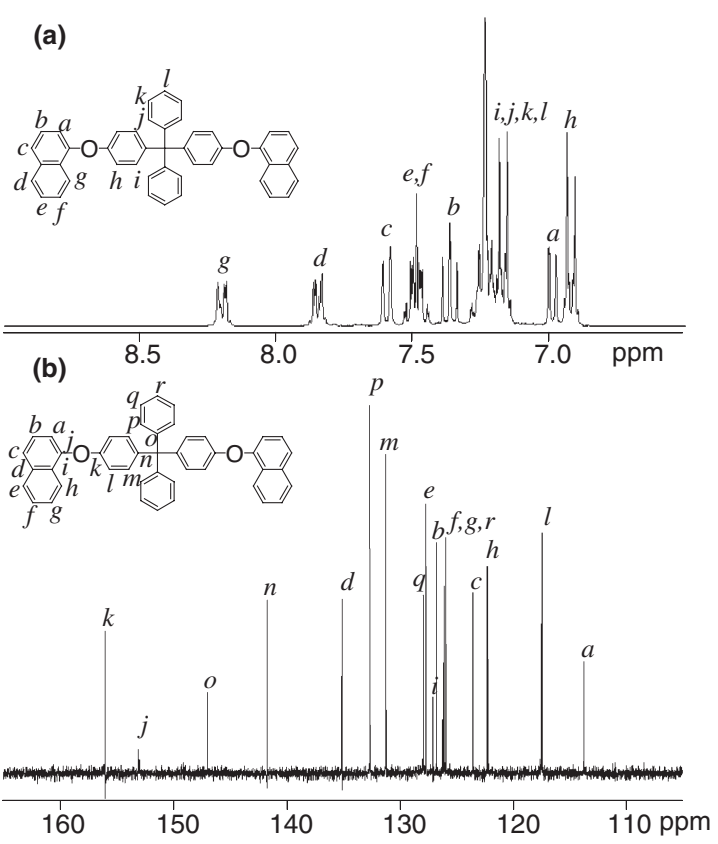

Figure 1. (a) ${ }^{1} \mathrm{H}$ NMR and (b) ${ }^{13} \mathrm{C}$ NMR spectrum of monomer 1 in $\mathrm{CDCl}_{3}$.

Table I. Synthesis of polymer $2^{\mathrm{a}}$

\begin{tabular}{ccccccc}
\hline Run & Solvent & $\begin{array}{c}\mathrm{FeCl}_{3} \\
(\text { equiv. }\end{array}$ & $\begin{array}{c}\text { Temp. } \\
\left({ }^{\circ} \mathrm{C}\right)\end{array}$ & $\begin{array}{c}\text { Time } \\
(\mathrm{h})\end{array}$ & $M_{\mathrm{n}}{ }^{\mathrm{b}}$ & $M_{\mathrm{w}} / M_{\mathrm{n}}{ }^{\mathrm{b}}$ \\
\hline 1 & Nitrobenzene & 2.2 & 25 & 24 & 3,000 & 1.9 \\
2 & Nitrobenzene & 2.5 & 25 & 24 & 4,200 & 2.4 \\
3 & Nitrobenzene & 3.0 & 25 & 24 & 4,000 & 3.4 \\
4 & Nitrobenzene & 2.5 & 60 & 24 & 1,800 & 1.8 \\
5 & Nitrobenzene & 2.5 & 25 & 48 & 4,000 & 2.0 \\
6 & $\mathrm{C}_{2} \mathrm{H}_{2} \mathrm{Cl}_{4}{ }^{\mathrm{c}}$ & 2.5 & 25 & 24 & 9,600 & 2.3 \\
7 & $\mathrm{C}_{2} \mathrm{H}_{2} \mathrm{Cl}_{4}{ }^{\mathrm{c}}$ & 2.5 & 60 & 24 & 6,500 & 2.1 \\
8 & $\mathrm{C}_{2} \mathrm{H}_{2} \mathrm{Cl}_{4}{ }^{\mathrm{c}}$ & 2.5 & 25 & 48 & 19,000 & 2.3 \\
\hline
\end{tabular}

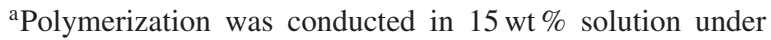
$\mathrm{N}_{2}$ atmosphere. ${ }^{b}$ Determined by GPC eluted with chloroform using polystyrene standard. ${ }^{\mathrm{c}} 1,1,2,2$-tetrachloroethane.

ence $(\mathrm{Ag} / \mathrm{AgCl})$, a working ( $\mathrm{Pt}$ wire), and a counter electrode (Pt spiral). The cyclic voltammogram of 1 reveals that the oxidation potential of 1 is $1.6 \mathrm{~V}$, which is a similar value to that of monomers corresponding to polymer 3 or 4 .

Judging from one electron oxidation potential of 1 , we selected iron (III) chloride as an oxidant.

\section{Polymer Synthesis}

Oxidative coupling polymerization of 1 was carried out in the presence of $\mathrm{FeCl}_{3}$ under nitrogen atmosphere (Scheme 2). The results are summarized in Table I. Oxidative coupling polymerization requires theoretically 2-equiv of $\mathrm{FeCl}_{3}$ based on a monomer. The excess amount of $\mathrm{FeCl}_{3}$ generally increase the rate of polymerization, however, unfavorable gelation may occur due to the extra oxidation of polymers. Therefore, the amount of $\mathrm{FeCl}_{3}$ is an important factor 
for oxidative coupling polymerization. When 2.5 equivalent of iron (III) chloride to monomer 1 in nitrobenzene was used, a number-average molecular weight $\left(M_{\mathrm{n}}\right)$ of polymer 2 reached to 4,000 . On the other hand, polymerization in 1,1,2,2-tetrachloroethane, which is a better solvent for polymer 2 , proceeded smoothly at room temperature, producing quantitatively polymer 2 with the number-average molecular weight $\left(M_{\mathrm{n}}\right)$ and polydispersity of 19,000 and 2.3, respectively, after $48 \mathrm{~h}$.

\section{Polymer Characterization}

Polymer 2 was white solids and soluble in toluene, chloroform, and tetrahydrofuran (THF). The transparent self-standing film of 2 was prepared from toluene solution. The molecular model of the dimer shown in Scheme 2 illustrates that the highly kinked structure promises to possess high free volumes.

The structure of polymer 2 was identified by IR and NMR spectroscopy. The IR spectrum of 2 showed characteristic absorptions at 1234 and $1589 \mathrm{~cm}^{-1}$ due to $\mathrm{C}-\mathrm{O}$ and $\mathrm{C}=\mathrm{C}$ stretchings of the naphtyl ether unit, respectively. Elemental analysis also supported the formation of the expected polymer. The microstructure of polymer 2 was investigated by NMR spectroscopy $\left({ }^{1} \mathrm{H},{ }^{13} \mathrm{C}\right.$, DEPT45). The signal assigned to $c$-positioned proton at $7.60 \mathrm{ppm}$ disappears in the ${ }^{1} \mathrm{H}$ NMR spectrum of 2, while the signal assigned to $d$-positioned proton at $7.85 \mathrm{ppm}$ shifts to upfield (7.4 ppm) in polymer 2 (Figure 2a). In the ${ }^{13} \mathrm{C}$ NMR spectrum of 2 (Figure 2b), all the signals are observed at similar chemical shifts to monomer assignment except para-positioned carbon $(c)$ of the 1-oxynaphthylene unit which significantly shifts from 123.40 ppm for monomer 1 to $133.49 \mathrm{ppm}$ in polymer 2 . Moreover, this signal disappears completely in ${ }^{13} \mathrm{C} /$ DEPT45 NMR spectrum shown in Figure 2c, which clearly proves that this carbon changed to the quaternary one. These findings indicate that oxidative coupling reaction selectively occurs at para-position of the 1-oxynaphthylene moiety of 1 , giving the regiocontrolled linear polymer.

Since the relationship between electronic structure and the backbone conformation is a interesting feature of conjugation polymers. Figure 3 shows the UV-vis absorption spectrum of polymer 2 with a peak top at $350 \mathrm{~nm}$. This spectrum is quite similar to that of 1 , which indicates a small extension of $\pi$-conjugation in polymer 2 This suggests the dihedral angle between neighboring naphthalene rings may be very large because of the steric hindrance of the naphthalene rings. On the other hand, the photoluminescence (PL) spectrum of polymer 2 shows a very smooth peak without any shoulders, indicating no interaction between polymer main chains.
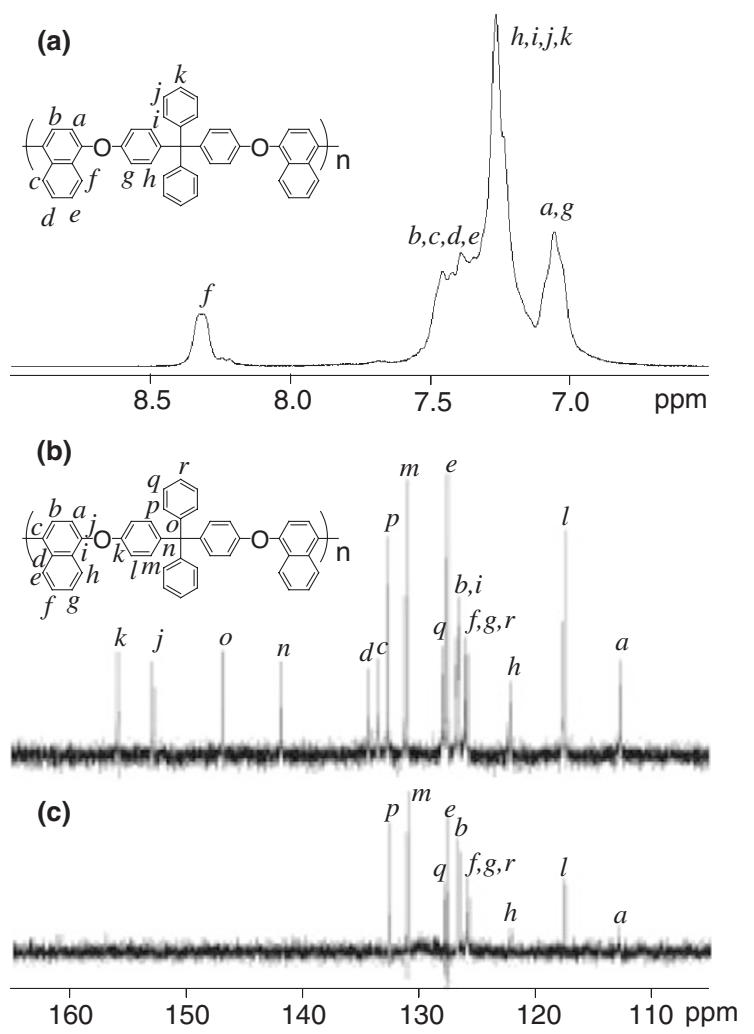

Figure 2. NMR spectra of polymer 2 in $\mathrm{CDCl}_{3}$; (a) ${ }^{1} \mathrm{H} \mathrm{NMR}$, (b) ${ }^{13} \mathrm{C}$ NMR and (c) ${ }^{13} \mathrm{C} / \mathrm{DEPT} 45 \mathrm{NMR}$ spectrum of 2.

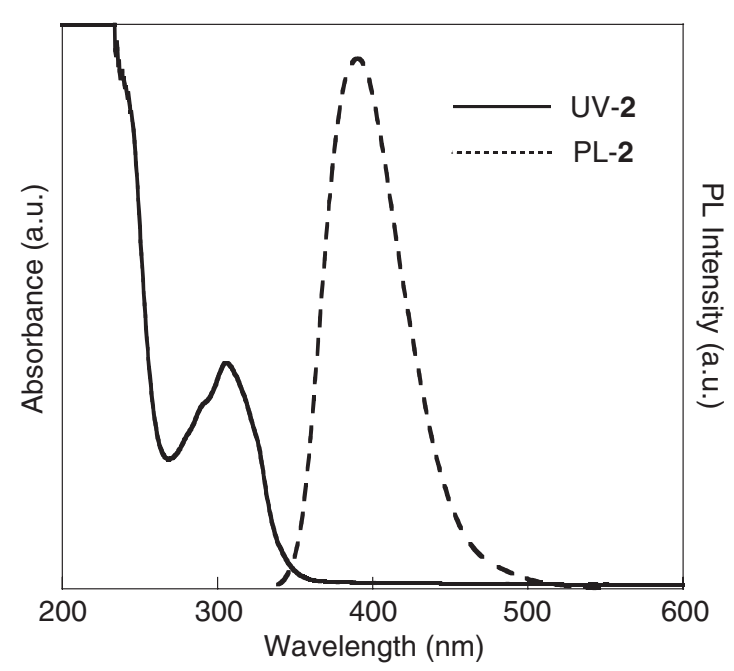

Figure 3. UV-vis absorption (bold line, $1 \times 10^{-7} \mathrm{M}$ ) and photoluminescence (broken line, $1 \times 10^{-7} \mathrm{M}$ ) of polymer 2 in chloroform solution.

\section{Thermal Stability}

The thermal stability of polymer 2 was examined by thermogravimetry (TG) and differential scanning calorimetry (DSC) analyses (Figure 2). In TG profile the polymer showed high decomposition temperature at $534{ }^{\circ} \mathrm{C}$ with $5 \%$ weight loss. The glass transition temperature $\left(T_{g}\right)$ of 2 was observed at $252^{\circ} \mathrm{C}$ in DSC trace on the second heating. 


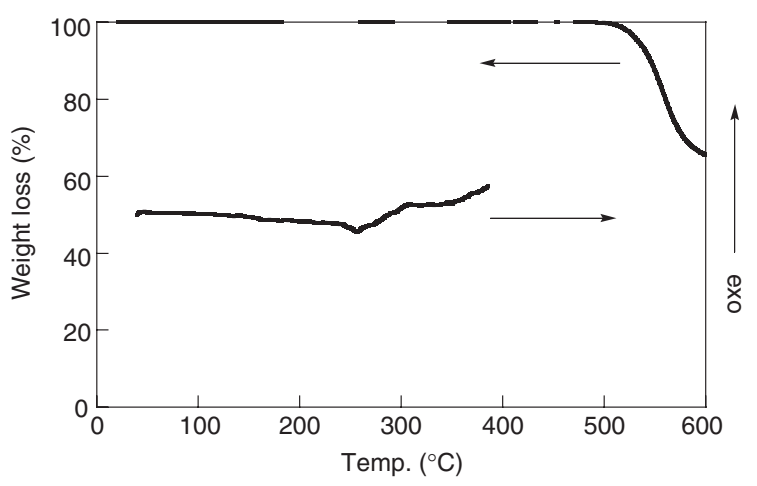

Figure 4. TGA and DSC (2nd scan) traces of polymer 2 $\left(10^{\circ} \mathrm{C} / \mathrm{min}\right.$ under nitrogen).

Table II. Refractive indices and $\varepsilon$ values of polymer 2,3 , and 4

\begin{tabular}{ccccccc}
\hline Polymer & $d(\mu \mathrm{m})^{\mathrm{a}}$ & $n_{\mathrm{TE}}{ }^{\mathrm{b}}$ & $n_{\mathrm{TM}^{\mathrm{c}}}$ & $n_{\mathrm{AV}}{ }^{\mathrm{d}}$ & $\varepsilon_{\mathrm{Op}}{ }^{\mathrm{e}}$ & $\varepsilon^{\mathrm{f}}$ \\
\hline 2 & 3.3 & 1.643 & 1.638 & 1.642 & 2.69 & 2.75 \\
3 & 5.0 & 1.622 & 1.556 & 1.600 & 2.56 & 2.93 \\
4 & 5.0 & 1.614 & 1.608 & 1.612 & 2.60 & 2.50 \\
\hline
\end{tabular}

${ }^{\mathrm{a}}$ Film thickness. ${ }^{\mathrm{b}}$ The in-plane refractive indices. ${ }^{\mathrm{c}}$ The outof-plane refractive indices. ${ }^{\mathrm{d}}$ Average refractive indices; $n_{\mathrm{AV}}=$ $\left(2 n_{\mathrm{TE}}+n_{\mathrm{TM}}\right) / 3$. ${ }^{\mathrm{e}}$ Optically estimated dielectric constant; $\varepsilon=$ $n^{2}$ AV. ${ }^{\mathrm{f}}$ Dielectric constant calculated from capasitance.

\section{Refractive Index and Dielectric Constant}

Finally the physical properties of poly(naphthylene ether)s were summarized in Table II. The refractive index $(n)$ of 2 was measured at the wavelength of $1.32 \mu \mathrm{m}$ using a prism coupler. The average refractive index value of $n$ is 1.64 . The optically estimated $\varepsilon_{\mathrm{op}}$ at $1 \mathrm{MHz}$ is determined to be 2.69 , according to the following equation; $\varepsilon_{\mathrm{op}}=n^{2},{ }^{10}$ which is similar to that of polymer 3 and 4 .

In order to measure the $\varepsilon$ value of 2 directly, the polymer film with a thickness of $1.3 \mu \mathrm{m}$ was spincoated onto a silicon wafer from its toluene solution. The average $\varepsilon$ value was determined from its capacitance to be 2.75 (1 MHz). Recently, polymers containing triptycene (5) was reported to be low- $\kappa$ materials $(\varepsilon=2.78,10 \mathrm{kHz})$, because triptycene has restricted rotation by multiple point attachment to the polymer backbones, and introduces free volume at the molecular scale..$^{5}$ The $\varepsilon$ value of 2 is comparable to that of polymer 5, which means polymer 2 has large free volumes, and, however, is larger than that of polymer 4. These results are summarized in Table II.

The presence of free volume in polymers 2 and 4 was confirmed by BET gas absorption studies that revealed a surface area for powders polymers 2 and 4 of 124 and $137 \mathrm{~m}^{2} / \mathrm{g}$ respectively. Since polymers generally show the surface area less than $20 \mathrm{~m}^{2} / \mathrm{g},{ }^{11}$ these results clearly indicate that these polymers involve much free volume.

\section{CONCLUSIONS}

A novel monomer 4,4'-bis(1-naphthyloxy)tetraphenylmethane 1 was prepared from 4,4'-dihydroxytetraphenylmethane and 1-bromonaphthalene by the Ullmann reaction. New naphthylether polymer 2 that has binaphthyl backbone in the main chain was obtained from monomer 1 by oxidative coupling polymerization using iron (III) chloride as an oxidant. The number-average and weight-average molecular weights of polymer 2 were 19,000 and 43,000 , respectively. The polymer was capable of making self-standing film by casting from toluene solution, and showed high thermal stability and the low dielectric constant.

Acknowledgment. The authors would like to express the gratitude to Dr. Yoshimasa Sakai (Mitsubishi Chemical Co. Ltd.) for the $\varepsilon$ measurements as well as to Mr. Kazuyuki Maeda for measurements of nitrogen adsorption isotherms.

\section{REFERENCES}

1. C. E. Sroog, Prog. Polym. Sci., 16, 561 (1991).

2. G. Maier, Prog. Polym. Sci., 16, 3 (2001).

3. Y. Watanabe, Y. Shibasaki, S. Ando, and M. Ueda, Polym. J., 38, 79 (2006).

4. C. V. Nguyen, K. R. Carter, C. J. Hawker, J. L. Hedrick, R. L. Jaffe, R. D. Miller, J. F. Remenar, H.-W. Rhee, P. M. Rice, M. F. Toney, M. Trollsas, and D. Y. Yoon, Chem. Mater., 11, 3080 (1999).

5. T. M. Long and T. M. Swager, J. Am. Chem. Soc., 125, 14113 (2003).

6. S. J. Martin, J. P. Godschalx, M. E. Mills, E. O. Shaffer, and P. H. Townsend, Adv. Mater., 12, 1769 (2000).

7. Y. Sasada, Y. Shibasaki, M. Suzuki, and M. Ueda, Polymer, 44, 355 (2003).

8. K. Tsuchiya, H. Ishii, Y. Shibasaki, S. Ando, and M. Ueda, Macromolecules, 37, 4794 (2004).

9. Z. B. Li and M. Ueda, Kobunshi Ronbunshu, 41, 117 (1984).

10. D. Boese, H. Lee, D. Y. Yoon, J. D. Swallen, and J. F. Rabolt, J. Polym. Sci., Part B: Polym. Phys., 30, 1321 (1992).

11. R. Wolf and C. S. Marvel, J. Polym. Sci., Polym. Chem. Ed., 7, 2481 (1969). 